\title{
The Effect of Cryogenic Freezing Followed by Gamma Radiation on the Survival of Salmonella spp. on Frozen Shrimp
}

\author{
Christopher H. Sommers ${ }^{1 *}$, Kathleen T. Rajkowski', Shiowshuh Sheen ${ }^{1}$, Charles Samer ${ }^{2}$ and Eric Bender ${ }^{2}$
}

${ }^{1}$ Eastern Regional Research Center, U.S. Department of Agriculture, Agricultural Research Service, Wyndmoor, Pennsylvania, USA ${ }^{2}$ Air Products and Chemicals, Inc, Allentown, Pennsylvania, USA

\begin{abstract}
Unfortunately, contraction of food borne illness due to consumption of contaminated seafood, including shrimp, is an occasional occurrence. Cryogenic freezing and gamma irradiation are safe and effective technologies that can be used to control and inactivate pathogenic bacteria in foods. In this study, the effect of cryogenic freezing and gamma irradiation for inactivation of Salmonella spp. on shrimp was investigated. We found that cryogenic freezing of raw shrimp $\left(-82^{\circ} \mathrm{C}, 3 \mathrm{~min}\right)$, using a pilot scale industrial liquid nitrogen freezer, resulted in a 1.27 log reduction of Salmonella spp. on whole shrimp, which was maintained during 12 weeks of frozen storage $\left(-20^{\circ} \mathrm{C}\right)$. During our evaluation of selective microbiological media for recovery and enumeration of Salmonella spp. we found that Brilliant Green Sulfur Agar produced results indistinguishable from that of non-selective Tryptic Soy Agar when determining the effect of cryogenic freezing on Salmonella spp. survival. Radiation $\mathrm{D}_{10}$ values for Salmonella spp. on frozen shrimp were approximately $0.56 \mathrm{kGy}$. Cryogenic freezing $\left(-82^{\circ} \mathrm{C}\right)$, followed by gamma irradiation $(2.25$ kGy) produced a $>5$ log reduction of Salmonella spp., and that reduction was maintained during 12 weeks frozen storage $\left(-20^{\circ} \mathrm{C}\right)$. These results indicate that both cryogenic freezing and gamma irradiation contribute to inactivation of Salmonella spp. on frozen shrimp.
\end{abstract}

Keywords: Gamma radiation; Cryogenic freezing; Shrimp; Salmonella

\section{Introduction}

The United States imported approximately 1.2 billion pounds of shrimp in 2008 , at a value of $\$ 4.1$ billion, with the majority of noncanned shrimp being imported in the frozen form, and the per capita consumption of shrimp (all forms) estimated to be approximately 4.1 lbs [1]. While consumption of shrimp and other seafood is significantly less than meat and poultry, food borne illness associated with consumption of seafood can occur on occasion [2,3]. Consumption of shrimp contaminated with Salmonella spp. has been associated with many food borne illness outbreaks, and that $0.5-34.4 \%$ of shrimp products, sold in multiple nations, at the retail level, and from processors and exporters, tested positive for Salmonella [4]. Shrimp accounted for approximately $58 \%$ of imported seafood quarantined for Salmonella (considered to be an adulterant) contamination by the U.S. Food and Drug Administration (FDA), while lobster accounted for 5\%, tilapia $4 \%$, and squid $3 \%[5]$.

A recent study conducted by the FDA concluded that antibiotic resistant Salmonella were readily isolated from imported foods, primarily of seafood origin, and that continued surveillance of foodborne zoonotic bacterial pathogens from imported foods entering the United States is required [4]. Noda et al. [6] found that Salmonella populations on shrimp decreased during long-term frozen storage, but were still recoverable, and that storage temperature affected the recovery of the pathogen. It is relatively easy to isolate Salmonella spp. from many types of tropical and non-tropical seafood including retail frozen shrimp, lobsters, cuttlefish, catfish, and seer fish [7-9].

Ionizing (gamma) irradiation is a safe and effective process that has been approved in many countries to improve the microbiological safety and shelf-life of foods [10]. In the U.S, a petition to allow irradiation of crustaceans is currently being evaluated by the FDA
[11]. While there is a great deal of data available regarding irradiation of seafood, the majority of the published studies target refrigerated, as opposed to frozen seafood [12]. The majority of raw seafood sold in the U.S. is either frozen or previously frozen. Additional research is needed to determine radiation $D_{10}$ values of food borne pathogens on raw frozen seafood such as shrimp. While treatment of foods with gamma irradiation is an effective intervention technology, the effect of freezing on pathogen survival in frozen meat, poultry, and seafood is less clear as most published studies did not use pilot scale commercial freezing equipment, but laboratory scale freezers [13-16]. Additional research is needed to determine the effect of quick freezing on food borne pathogen survival.

The purpose of this study was to: 1) Determine the effect of cryogenic freezing $\left(-82^{\circ} \mathrm{C}\right)$ on the survival of Salmonella spp. inoculated onto raw whole shrimp using pilot scale commercial equipment; 2) To determine the radiation $\mathrm{D}_{10}$ for Salmonella spp. isolated from seafood in frozen shrimp; 3) To determine the effect of freezing and irradiation for Salmonella inoculated onto shrimp during long-term frozen storage $\left(-20^{\circ} \mathrm{C}\right)$; and 4$)$ Evaluate selective and non-selective microbiological media for use in cryogenic freezing studies.

${ }^{*}$ Corresponding author: Christopher H. Sommers, Food Safety and Intervention Technologies Research Unit, Eastern Regional Research Center, USDA-ARS 600 East Mermaid Lane, Wyndmoor, PA 19038, Tel: 215-836-3754; Fax: 215-233 6445; E-mail: Christopher.sommers@.ars.usda.gov

Received September 24, 2011; Accepted November 25, 2011; Published December 01, 2011

Citation: Sommers CH, Rajkowski KT, Sheen S, Samer C, Bender E (2011) The Effect of Cryogenic Freezing Followed by Gamma Radiation on the Survival of Salmonella spp. on Frozen Shrimp. J Food Process Technol S8-001. doi:10.4172/2157-7110.S8-001

Copyright: (C) 2011 Sommers $\mathrm{CH}$, et al. This is an open-access article distributed under the terms of the Creative Commons Attribution License, which permits unrestricted use, distribution, and reproduction in any medium, provided the original author and source are credited. 


\section{Materials and Methods}

\section{Bacterial strains}

The Salmonella isolates used in this study, were isolated from seafood, including shrimp, were obtained from the U.S. Food and Drug Administration and included Salmonella Schwarzengrund, S. Bahrenfeld, S. Weltevreden, and S. Panama. Identity of the isolates was confirmed by Gram stain, followed by analysis with Gram positive or negative identification cards using the Vitek Automicrobic System (bioMerieux Vitek, Inc, Hazelwood MO). The bacterial strains were cultured on Tryptic Soy Agar (TSA, BBL/Difco, Inc., Sparks, MD) at $37^{\circ} \mathrm{C}$ and maintained at $0-4^{\circ} \mathrm{C}$ until use.

\section{Shrimp}

The shrimp was purchased from an internationally-recognized retailer with a strong quality assurance program. The shrimp were kept frozen $\left(-20^{\circ} \mathrm{C}\right)$ and irradiated to a radiation dose of $10 \mathrm{kGy}$ for inactivation of background microflora as described below [17]. Irradiation of the shrimp to $10 \mathrm{kGy}$ decreased the background microflora to less than $0.1 \mathrm{CFU} / \mathrm{g}$. The shrimp were thawed overnight in a refrigerator $\left(4^{\circ} \mathrm{C}\right)$ prior to inoculation.

\section{Bacterial growth and inoculation}

The procedure for inoculation, irradiation, and enumeration of bacteria was followed as published previously $[17,18]$. Each bacterial strain was cultured independently in 25-mL of Tryptic Soy Broth (TSB, BBL/Difco Laboratories, Sparks, MD) in baffled 500-mL sterile flasks at $37^{\circ} \mathrm{C}(150 \mathrm{rpm})$ for $18 \mathrm{~h}$. The bacterial cells were then diluted into four liters of sterile distilled water in a sterile polypropylene pan. The thawed shrimp were then dip-inoculated in the same species mixture for approximately $30 \mathrm{~min}$. The excess fluid was then allowed to drip off; the shrimp placed in a separate sterile polypropylene pan, and kept on ice until cryogenic freezing. This procedure resulted in approximately $7 \log _{10}$ CFU/g of the Salmonella spp. multi-isolate cocktail being inoculated onto the shrimp. Samples (six shrimp) were then removed to assess Salmonella levels, and served as the untreated controls for determination of $\log _{10}$ reduction as described below.

\section{Freezing}

For the freezing study, the inoculated whole shrimp were cryogenically frozen $\left(-82^{\circ} \mathrm{C}\right)$ for 3 min using a Cryo-Test Chamber (Air Products and Chemicals, Allentown, PA USA), which exposed the shrimp to liquid nitrogen vapor in a controlled manner. The frozen shrimp samples (six shrimp, approximately $21 \mathrm{~g}$ each) were then placed in individual polynylon bags (Uline, Inc., Philadelphia, PA) which were sealed using a Multivac A300 packager (Kansas City, MO) and kept frozen at $-20^{\circ} \mathrm{C}$ with sufficient bags of frozen shrimp to complete an experimental replicate lasting three months. This entire procedure was then repeated five times $(n=5)$.

\section{Gamma irradiation}

A Lockheed Georgia Company (Marietta, GA) self-contained ${ }^{137} \mathrm{Cs}$ radiation source was used for all exposures. The radiation source consisted of 23 individually sealed source pencils placed in an annular array. The $22.9 \mathrm{~cm} \times 63.5 \mathrm{~cm}$ cylindrical sample chamber was located central to the array when placed in the operating position. The dose rate was $0.082 \mathrm{kGy} / \mathrm{min}$, which was determined using ISO/ASTM Standard 51900-019 in cooperation with the National Institute of Standards and Tests (NIST). The temperature during irradiation was maintained at $-20^{\circ} \mathrm{C}$ by the gas phase of a liquid nitrogen source that was introduced directly into the top of the sample chamber [5]. To ensure that uniform radiation dose was delivered, sample bags were placed centrally and vertically within the cylindrical chamber. Because of the irradiator design, dose uniformity-ratio's (DUR's) were less than 1.1: 1.0 for the samples types used in this study. The temperature was monitored using two thermocouples placed on the side of the sample bags. The radiation absorbed dose was then verified using radio chromic film dosimeters (Far West, Inc., Goleta, CA).

\section{Enumeration of bacteria}

Following freezing and irradiation, the samples were assayed for surviving bacteria by standard microbiological procedures. The shrimp samples were allowed to thaw at room temperature, approximately $25^{\circ} \mathrm{C}$. Ninety- $\mathrm{mL}$ of sterile BPB was then added to sample bags that contained $10 \mathrm{~g}$ of inoculated sample, and the sample mixed by stomaching for $90 \mathrm{~s}$ (Seward, UK). The samples were then serially diluted in BPB, using tenfold dilution, and $0.1-\mathrm{mL}$ of diluted sample was surface plated onto TSA, Brilliant Green Sulfur Agar (BGSA), XLT-4, or Hektoen Agar (BD-Difco, Sparks, MD). Three 0.1-mL aliquots were plated per dilution. The plates were then incubated for $24-48 \mathrm{~h}$ at $37^{\circ} \mathrm{C}$ prior to enumeration.

\section{$\mathrm{D}_{10}$ values}

The average CFU/g of an irradiated sample $(\mathrm{N})$ was divided by the average $\mathrm{CFU} / \mathrm{g}$ of the untreated control $\left(\mathrm{N}_{\mathrm{o}}\right)$ to produce a survivor ratio $\left(\mathrm{N} / \mathrm{N}_{\mathrm{o}}\right)$. The untreated controls were the Salmonella spp. Inoculated onto the shrimp and then frozen for one week. Radiation $\mathrm{D}_{10}$ value is defined as the radiation dose required to achieve a $90 \%$ reduction in viable microorganism. Radiation $\mathrm{D}_{10}$ values were determined by calculating the reciprocal of the slope of the $\log _{10}\left(\mathrm{~N} / \mathrm{N}_{\mathrm{o}}\right)$ ratios versus irradiation dose [10].

\section{Statistical analysis}

Each experiment was conducted independently five times $(n=5)$. Determination of $\mathrm{D}_{10}$, descriptive statistics, and analysis of variance (ANOVA) were completed using Microsoft Excel Office 2000 (Microsoft Corp, Redmond, WA).

\section{Results and Discussion}

The majority of seafood and aquaculture products purchased in the U.S. are purchased as either frozen or previously frozen, and cryogenic freezing of shrimp is an effective means for maintaining product quality, even under repeated freezing and thawing [19]. Some studies indicate that cryogenic freezing may be used to inactivate food-borne pathogens and spoilage microorganisms [13-16]. However, very few, if any, of these studies utilized commercial quality cryogenic freezing equipment. There is very little literature available that has investigated the use of selective media on recovery of Salmonella spp. from frozen foods. Therefore we investigated the effect of cryogenic freezing, and the effect of the microbiological media, including tryptic soy agar (TSA) as a non-selective recovery medium and Brilliant Green Sulfur Agar (BGSA), Hektoen Agar (HA), and XLT-4 as the selective media to recover and enumerate Salmonella spp. from non-irradiated and irradiated frozen shrimp.

When the shrimp were cryogenically frozen $\left(-82^{\circ} \mathrm{C}\right)$, stored for one week $\left(-20^{\circ} \mathrm{C}\right)$, and the Salmonella spp. recovered and enumerated using TSA, BGSA, HA, and XLT-4 media, the $\log _{10}$ reductions were $1.27(+0.09), 1.26(+0.10), 1.82(+0.07)$, and $1.96(+0.08)$, respectively. 
The log reductions obtained using HA and XL-4 and were statistically greater than those obtained using TSA and BGSA (ANOVA, $n=5$, $\mathrm{p}<0.05)$. In contrast, the log reductions obtained using TSA and BGSA were statistically similar. The difference in log reductions and recovery (approximately $0.6 \log _{10}$ ) were maintained during frozen storage regardless of whether the shrimp were non-irradiated, irradiated to a dose of $1.5 \mathrm{kGy}$, or irradiated to a dose of $3.0 \mathrm{kGy}$ (Figure 1). Therefore, we recommend the use of BGSA as a selective medium for the enumeration of Salmonella spp. after cryogenic freezing as opposed to HA and XLT-4.

The effect of selective microbiological agars on gamma radiation $\mathrm{D}_{10}$ values has been determined in our laboratory using a number of food borne pathogens (Sommers and Boyd (2006); Sommers, unpublished data). In this study, the $\mathrm{D}_{10}$ values for Salmonella spp. on frozen shrimp were $0.56(+0.02), 0.56(+0.02), 0.55(+0.03)$ and $0.46(+0.03)$ using TSA, BGSA, HA, and XLT-4, respectively. This is in agreement with results previously obtained in our laboratory that XLT-4 agar can sometimes provide statistically lower $\mathrm{D}_{10}$ values than other selective media.

The National Advisory Committee on Microbiological Safety of

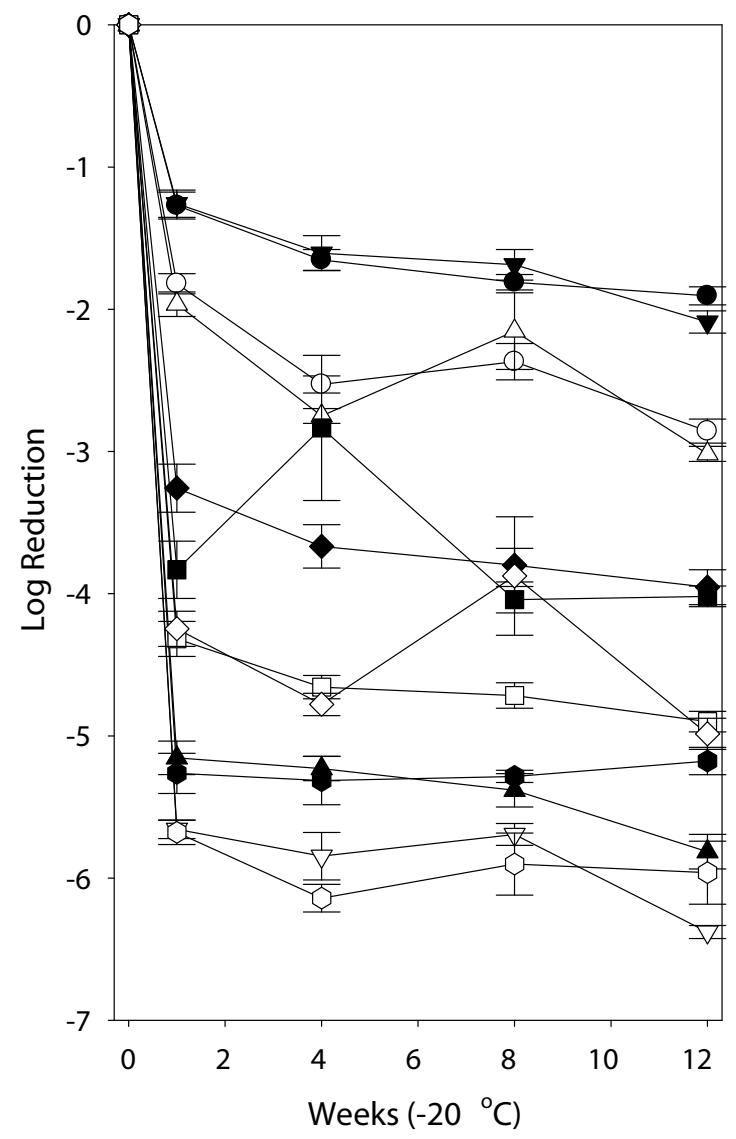

Figure 1: The Effect of Cryogenic Freezing and Gamma Radiation on the Survival of Salmonella spp. using Different Recovery Media. Each experiment was conducted independently 5 times $(n=5)$. Standard error of the mean is shown as error bars. Time 0 is when samples were irradiated. TSA0 kGy (closed circle); BGSA-0 kGy (inverted closed triangle); HA-0 kGy (open circle); XLT-4-0 kGy (open triangle). TSA-1.5 kGy (closed square); BGSA$1.5 \mathrm{kGy}$ (closed diamond); HA-1.5 kGy (open diamond); XLT-4-1.5 kGy (open triangle). TSA-3 kGy (closed triangle); BGSA-3 kGy (closed pentagon); HA-3 kGy (inverted open triangle); XLT-4-3 kGy (open pentagon).
Foods (NACMCF) recommends a five log reduction of food borne pathogens for a food to be called pasteurized when using non thermal process interventions. Frequently, the minimum radiation dose needed to produce a five log reduction is calculated using a $\mathrm{D}_{10}$ value [10]. An alternative is to calculate the $\log _{10}$ reduction directly. In either case, care must be taken to account for and separate the effect of individual intervention technologies (e.g. freezing vs. gamma radiation), and the microbiological media used that may affect the calculation of either $\mathrm{D}_{10}$ or $\log _{10}$ reductions. For inactivation of Salmonella spp. on frozen shrimp using gamma irradiation, the use of BGSA as the selective agar provided the best results when compared to non-selective TSA medium. When calculating only $\mathrm{D}_{10}$, independent of freezing, we have found both BGSA and HA to be acceptable as Salmonella selective media.

Gamma irradiation of frozen shrimp for inactivation of Salmonella spp. yielded interesting results. The radiation $\mathrm{D}_{10}$ values obtained for Salmonella spp. inoculated onto shrimp (0.46-0.56 kGy) are in agreement with radiation $\mathrm{D}_{10}$ values $(0.47-0.70 \mathrm{kGy})$ for Salmonella spp. on a variety of frozen seafood products [18]. When the effect of cryogenic freezing on the survival of Salmonella spp. is included, a radiation dose of $3.0 \mathrm{kGy}$ would be needed to produce a five $\log _{10}$ reduction of Salmonella on whole shrimp and other frozen crustaceans and fish. At the gamma radiation dose of $3.0 \mathrm{kGy}$ used in the storage study, the numbers of Salmonella spp. recovered were at the lower limit of detection for the methodology used (Figure 1).

A radiation dose of $4 \mathrm{kGy}$ produced a $>6 \log _{10}$ reduction of Salmonella Enteriditis, inoculated onto shrimp [20], while another report recommended a radiation dose of $3.5 \mathrm{kGy}$ for a $5 \log _{10}$ reduction of Salmonella spp. [21], and a third study recommended a radiation dose of $3.5 \mathrm{kGy}$ for complete inactivation of Salmonella spp. on frozen shrimp [22]. Those studies did not account for the effect of cryogenic freezing on Salmonella spp. survival. The radiation doses needed to produce a five log reductions of Salmonella spp. on frozen shrimp typically have no, or negligible, effects on the chemistry or quality of the product [19-23].

\section{Conclusions}

In this study, we determined that cryogenic freezing $\left(-82^{\circ} \mathrm{C}\right)$ of shrimp inactivated approximately $1.27 \log _{10}$ of Salmonella spp. using a industrial pilot scale equipment, and that $\log _{10}$ reduction was maintained during 12 weeks of frozen storage $\left(-20^{\circ} \mathrm{C}\right)$. Additionally, when the effect of freezing on Salmonella spp. was accounted for, the radiation $\mathrm{D}_{10}$ for Salmonella spp. on shrimp was approximately 0.56 $\mathrm{kGy}$, which is consistent with $\mathrm{D}_{10}$ values obtained in previous studies in our laboratory [18]. Therefore, cryogenic freezing, in combination with a gamma radiation dose of $2.25 \mathrm{kGy}$, was sufficient to inactivate five $\log _{10}$ of Salmonella spp. on whole raw shrimp in this study. This information may be of value to seafood processors and radiation service providers during preparation of their Hazard Analysis and Critical Control Point Plans (HACCP), and regulatory agencies in the evaluation of pending petitions to allow irradiation of seafood products.

\section{References}

1. VanVorhees D (2009) Fisheries of the United States-2008. National Marine Fisheries Service Office of Science and Technology 1-118.

2. Anonymous (2008) Fish and shellfish cause most food borne illness outbreaks - CSPI. Food Production daily.

3. Butt AA, Aldridge KE, Sanders CV (2004) Infections related to the ingestion of seafood Part 1: Viral and bacterial infections. Lancet Infect Dis 4: 201-212. 
Citation: Sommers CH, Rajkowski KT, Sheen S, Samer C, Bender E (2011) The Effect of Cryogenic Freezing Followed by Gamma Radiation on the Survival of Salmonella spp. on Frozen Shrimp. J Food Process Technol S8-001. doi:10.4172/2157-7110.S8-001

4. Wan Norhana MN, Poole SE, Deeth HC, Dykes GA (2010) Prevalence, persistence, and control of Salmonella and Listeria in shrimp and shrimp products: A review. Food Control 21: 343-361.

5. Allhouse J, Buzby J, Harvey D, Zorn D (2004) Seafood safety and trade. USDAEconomic Research Service. Issues in Diet, Safety, and Health/ Agriculture Information Bulletin Number 789-797.

6. Noda H, Chisuwa M, Kaneko M, Onoue Y, Takatori K, et al. (2009) Survival of Salmonella Weltevreden and S. Senftentberg in black tiger shrimp under frozen storage. Shokuhin Eiseigaku Zasshi 50: 85-88.

7. Lyer T, Shrivastava K (1989) Incidence and low temperature survival of Salmonella in fishery products. Fishery Technology. Soc Fisheries Technol 26: 39-42.

8. Pinu FR, Yeasmin S, Latiful Bari Md, Rahman MM (2007) Microbiological conditions of frozen shrimp in different food market of Dhaka City. Food Sci Technol Res 13: 362-365.

9. Shabarinath S, Sanath-Kumar H, Khushiramani R, Karunasagar I (2007) Detection and characterization of Salmonella associated with tropical seafood. Int J Food Microbiol 114: 227-233.

10. Diehl J (1995) Safety of irradiated food. (2nd Ed.), Marcel Dekker, New York, New York, 93-98.

11. GAO (Government Accounting Office) (2010) Food Irradiation: FDA Could Improve Its Documentation and Communication of Key Decisions on Food Irradiation Petitions.

12. Arvanitoyannis IS, Stratakos A, Mente E (2009) Impact of irradiation on fish and seafood shelf-life: a comprehensive review of applications and irradiation detection. Crit Rev Food Sci Nutr 49: 68-112.

13. Domingez SA, Schaffner DW (2009) Survival of Salmonella in processed chicken products during frozen storage. J Food Prot 72: 2088-2092.

14. Dykes GA, Moorhead SM (2001) Survival of three Salmonella serotypes on beef trimmings during simulated commercial freezing and storage. J Food Safety 21: 87-96.
15. Escartín EF, Lozan, JS, Garcia OR (2000) Quantitative survival of native Salmonella serovars during storage of frozen raw pork. Int J Food Microbiol 10: $19-25$.

16. Rajkowski K, Samer C (2010) Effect of individual quick freezing (IQF) on Salmonella recovery and texture of shrimp. 2nd International Congress on Seafood Technology (ICST), Anchorage, AK.

17. Sommers CH, Niemira BA (2011) Inactivation of avirulant Yersinia pestis in beef bologna by gamma irradiation. J Food Prot 74: 627-630.

18. Sommers $\mathrm{CH}$, Rajkowski KT (2011) Radiation inactivation of food borne pathogens on frozen sea food products. J Food Prot 74: 641-644.

19. Boonsumrej S, Chaiwanichsiri S, Tantratian S, Suzuki T, Takai R (2007) Effects of freezing and thawing on the quality changes of tiger shrimp (Penaeus monodon) frozen by air-blast and cryogenic freezing. J Food Eng 80: 292-299.

20. Abreu VKG, Zapata JFF, Figueiredo EAT, Garruti DS, Freitas ER, et al. (2009) Gamma irradiation of frozen and packaged headed shrimp. J Food Quality 32 : 425-435.

21. Ito H, Rashid HO, Sangthon N, Adulyatham P, Rattagool P, et al. (1993) Effect of gamma-irradiation on frozen shrimps for decontamination of pathogenic bacteria. Rad Phys Chem 42: 279-282.

22. Nerkar DP, Bandekar JR (1989) Elimination of Salmonella from frozen shrimp by gamma irradiation. J Food Safety 10: 175-180.

23. Health Canada (2005) Irradiation of shrimp: summary of a submission process.

24. Lipp EK, Rose JB (1997) The role of seafood in food-borne diseases in the United States of America. Rev Sci Tech 16: 620-40.

25. NACMCF (National Advisory Committee on Microbiological Criteria for Food) (2006) Requisite scientific parameters for establishing the equivalence for alternative methods of pasteurization. J Food Prot 69:1190-1216.

26. Zhao S, Datta AR, Ayers S, Friedman S, Walker RD, et al. (2003) Antimicrobialresistant Salmonella serovars isolated from imported foods. Int J Food Microbiol 84: 87-92. 